\title{
The search for individualized smoking cessation therapy
}

\author{
Ilka Lopes Santoro ${ }^{1}$
}

"Giving up smoking is the easiest thing in the world. I know it because I've done it thousands of times."

Mark Twain

Although the prevalence of smoking in Brazil has been decreasing in recent decades, ${ }^{(1)}$ tobacco is a drug classified as licit; therefore, the epidemic of this neurobehavioral disease, caused by nicotine dependence, will probably endure for many decades to come. ${ }^{(2)}$ As with any epidemic, it is necessary to understand the disease behavior for different population groups in order to devise effective treatment and control strategies.

In this sense, it is important to emphasize that we are in the era of individualized therapies, it being essential to establish a risk classification for each subgroup of patients in order to outline the therapeutic strategies to be implemented for each of them. First, there is strong evidence that women are affected differently by tobacco compared to men, because women adhere more strongly to their smoking addiction. This occurs especially among those who are more vulnerable and those disadvantaged by low income or a low level of education. ${ }^{(3-5)}$ A second aspect that needs to be highlighted is that smoking addiction in women can be potentiated more by the sensorial and social context than by nicotine dependence, which means to say that, unlike males, females use tobacco to cope with negative emotions and situations or in an attempt to reduce stress or control weight. ${ }^{(6)}$

In order to make such an epidemiological assessment, the article entitled "Smoking among female sex workers: prevalence and associated variables", ${ }^{(7)}$ published in the current issue of the JBP, focuses on a specific subgroup of the Brazilian population that fits perfectly among the women most vulnerable to addiction. The authors were very happy in their choice of this object of study to describe the characteristics and prevalence of smoking in this population subgroup, a prevalence that was found to be much higher than the mean prevalence reported for the general Brazilian population (71.1\% vs. $10.4 \%$ ).

In addition, the authors sought to understand the pattern of tobacco use, reporting early age at smoking initiation, high daily tobacco consumption, with a high level of nicotine dependence, and low motivation for smoking cessation. They also investigated whether there were associations between smoking and mood disorders (anxiety, depression, and perceived stress).

Furthermore, although governmental interventions-such as increasing the prices of cigarette packs by increasing taxes-reduced cigarette sales by $32 \%$, the authors found that consumption of illicit cigarettes from Paraguay is a common practice in the subgroup in question.

In conclusion, it is important to note that, by establishing the behavior of female sex workers regarding tobacco use, the study by Devóglio et al. (7) raises a fundamental issue, which is that of structured planning developed specifically to address this highest risk subgroup. Therefore, not only should a cognitive behavioral approach and the use of pharmacotherapy be considered to improve the quality of life of these women but also the use of a harm reduction strategy. In addition, certain particularities of this subgroup should be taken into account, such as the need to reduce modifiable risk factors (use of alcohol and illicit drugs), which are also very prevalent, as well as the need to establish cigarette smuggling control policies.

\section{REFERENCES}

1. Levy D, de Almeida LM, Szklo A. The Brazil SimSmoke policy simulation model: the effect of strong tobacco control policies on smoking prevalence and smoking-attributable deaths in a middle income nation. PLoS Med. 2012;9(11):e1001336. https://doi.org/10.1371/journal. pmed. 1001336

2. Silva LC, Araujo AJ, Queiroz ÂM, Sales MD, Castellano MV; Comissão de Tabagismo da SBPT. Smoking control: challenges and achievements. J Bras Pneumol. 2016;42(4):290-8. https://doi.org/10.1590/S180637562016000000145

3. Higgins ST, Kurti AN, Redner R, White TJ, Gaalema DE, Roberts ME, et al. A literature review on prevalence of gender differences and intersections with other vulnerabilities to tobacco use in the United States, 2004-2014. Prev Med. 2015;80:89-100. https://doi.org/10.1016/j. ypmed.2015.06.009

4. Partnership for a Tobacco-free Main [webpage in the Internet]. Augusta:
Maine Center for Disease Control and Prevention [cited 2017 Jan 1]. US Department of Health and Human Services. Women and Smoking: a Report of the Surgeon General. 2002 [Adobe Acrobat document, 686p.]. Available from: http://www.tobaccofreemaine.org/channels/providers/ documents/WomenandSmoking_000.pdf

5. Lombardi EM, Prado GF, Santos Ude P, Fernandes FL. Women and smoking: risks, impacts, and challenges. J Bras Pneumol. 2011;37(1):118-28. https://doi.org/10.1590/S1806-37132011000100017

6. Japuntich SJ, Gregor K, Pineles SL, Gradus JL, Street AE, Prabhala R, et al. Deployment stress, tobacco use, and postdeployment posttraumatic stress disorder: Gender differences. Psychol Trauma. 2014;8(2):123-6. https://doi.org/10.1037/tra0000093

7. Devóglio LL, Corrente JE, Borgato MH, Godoy I. Smoking among female sex workers: prevalence and associated variables. J Bras Pneumol. 2017;43(1):6-13. 